Challenging appraisal orthodoxies: teacher evaluation and professional development in the United Arab Emirates

By Justine Mercer,

Centre for Educational Leadership and Management (CELM)

School of Education, University of Leicester

162 - 166 Upper New Walk, Leicester, LE1 7QA, United Kingdom.

Tel: ++ $44(0) 1162297526 \quad$ Fax: ++ $44(0) 1162297501$

Email: jem49@le.ac.uk

\begin{abstract}
This paper presents findings from a four-year study of faculty appraisal at two higher education institutions (HEIs) in the United Arab Emirates (UAE). It finds that neither teachers nor academic managers are opposed to evaluative appraisal, and, contrary to much of the literature, most are happy for evaluative and developmental elements to be combined. It then examines the apparent paradox of continuing professional development in a context where federally-funded HEIs have the money to attract more teachers than they need; the legal right to dismiss any of them for any reason; and a strong belief on the part of managers that hese particular students need and deserve only the very best teachers. It concludes that these features of the UAE context present a considerable challenge to the popular notion that people are an institution's most precious resource and need to be developed at every opportunity.
\end{abstract}

Key words: appraisal, teacher evaluation, professional development, Middle East Running Head: Challenging appraisal orthodoxies 


\section{Challenging appraisal orthodoxies: teacher evaluation and professional development in the United Arab Emirates}

\section{Introduction}

This paper reports some of the findings from a four-year study into faculty appraisal at two federally-funded higher education institutions (HEIs) in the United Arab Emirates (UAE). In particular, it discusses the extent to which academic managers and lecturers consider accountability models of appraisal appropriate to education, and how far the specific systems in place are seen as evaluative and/or developmental. It then goes on to examine the impact of evaluative models of appraisal and the paradox of continuing professional development in a context where HEIs have the money and the legal backing to dismiss teachers with impunity, on the grounds that only the very best practitioners can compensate for the dire previous educational experiences of their students.

The two institutions concerned operate in something of a hybridized "third space" (Gutierrez et. al., 1999) in that all the students are indigenous Gulf-Arab Muslims but almost all the academic staff, including the Provost / Director, were born and educated in what the institutions themselves describe as 'the West', meaning the USA, Canada, the UK, Ireland, South Africa, Australia and New Zealand. As a result, appraisal systems in the UAE appear superficially similar to those in the West, not least because the procedures and criteria have been explicitly modeled on the practices of Western HEIs. When researched further, however, appraisal of higher education personnel in the UAE is said to function differently than in Western institutions, because the 'hybridized' internal and external culture challenges developmental appraisal designed to support continuing professional development. 
Much has already been written about appraisal in post-compulsory education in Western countries; Randle \& Brady (1997a, 1997b) and Elliott \& Crossley (1997) report on studies of appraisal in UK Further Education, whilst Pollitt (1987), Rutherford (1988, 1992), Bryman et. al. (1991), Magennis (1993), Wilson \& Beaton (1993), Taylor (1997), Hughes (1998) and Deem $(1998,2000)$ all write about appraisal in UK higher education, with Hutchinson (1995) writing about Irish HE. Miles \& Hyle (1999) and Huberty (2000) report their findings on appraisal at American universities whilst Casey et. al. (1997), Currie \& Vidovich (2000) and Taylor (2001) do the same for Australian universities. These studies usually distinguish between evaluative and developmental appraisal, with the majority arguing that both approaches to appraisal are essential; many theorists go on to suggest that evaluative appraisal ought to occur at a different time to developmental appraisal, and use different procedures and instruments; most empirical studies, however, find the two approaches being used simultaneously because this is seen as less timeconsuming and / or more transparent.

As far as I am aware, nothing comparable to the works cited above has been published about higher education appraisal in the Middle East. This, in itself, provides a rationale for my paper, but the value of research from the UAE is greatly enhanced by the fact that the context allows the researcher to document precisely what happens when traditional assumptions about appraisal are challenged.

The first part of the paper describes the national and institutional context of the research, arguing that although the procedures used in the appraisal schemes may look very familiar, the value systems underpinning them are rather different. The second section reviews the 
literature on higher education appraisal to examine appropriate levels of evaluative appraisal and the relationship between appraisal and professional development. The third section outlines the methodology of the research, and the final section discusses the findings of the study and their implications for the concept of continuing professional development.

The literature uses a huge variety of terms, such as teacher appraisal, teacher evaluation, and performance management, and there is no consensus about precisely what each phrase means (Fidler, 1989, p.191). In this paper, therefore, I shall use the word 'appraisal' in the broadest possible sense to denote any form of structured process through which the performance of an individual staff member is examined, for whatever purpose, by the particular individual concerned and / or other people connected with his or her place of work.

\section{The Background}

\section{(i) The National Context}

The UAE, a federation of seven sheikhdoms, with an Islamic constitution, was formed in 1971, after the British withdrew from The Trucial Coast, an area of the Arabian Gulf they had administered since 1820. According to Hofstede's (1991; 1996; 2005) seminal analysis, Arab countries (including the UAE, Egypt, Lebanon, Libya, Kuwait, Iraq and Saudi Arabia) display high power distance (ranking joint $12^{\text {th }}$ out of 74 countries, low collectivism (as opposed to high collectivism, low individualism or high individualism), moderately strong uncertainty avoidance, and low masculinity (as opposed to high masculinity, low femininity or high femininity). In other words, in Arab countries, less 
powerful members of society generally expect and accept that power will be distributed unequally; individuals usually put the interests of the society before their own; there is little tolerance of ambiguity; and emotional gender roles are usually distinct, with men expected to be "assertive, tough and focused on material success" and women expected to be "modest, tender and concerned with the quality of life" (Hofstede, 2005, p.120).

More particularly, Findlow (2005, p.287) describes the cultural climate of the UAE as "schizophrenic", and goes on to argue that the "juxtaposition of the global and the local, indigenous and imported, traditional and modern, idealistic and pragmatic" evident in other Gulf countries is "particularly acute" in the UAE because of the way oil wealth has fuelled exponential economic growth. Before oil was discovered in Abu Dhabi in 1958, there was no electricity, no plumbing, no telephone system, no hospitals, no modern schools, no bridges and no metalloid roads. Today the country boasts first-world healthcare systems, both public and private, education for all, including internationallyrecognized universities, an extensive transport network, complete with grid-locked sixlane highways, and the most vibrant economy in the Middle East.

Such rapid expansion would not have been possible without a huge influx of expatriate workers, attracted, in the main, by highly competitive tax-free salaries, paid for by oil revenues. These 'guest workers' represent around $80 \%$ of the population, and all of them are subject to a system of 'sponsorship' which allows their local employer to terminate their services at any time, for any reason, with virtually no legal redress. They never acquire citizenship and must return home within 30 days of leaving their job. Trade unions are banned, and all higher education staff are employed on fixed-term contracts, usually lasting three years. As a result, expatriate academics working in the public sector, despite 
their high salaries, have absolutely no job security, a fact that greatly influences their perceptions of the appraisal schemes operating at their institutions.

\section{(ii) The Institutional Context}

The UAE's first university was established in 1977, with a male and female campus on adjacent sites. A second, all-female university, given the pseudonym Rihab University, was established some twenty one years later, in 1998. I was an inaugural member of staff and carried out my research during Rihab's second and third year of operation. I then changed jobs and undertook a similar two-year study at Al Fanar College, an institution that was established in 1997, as part of a network of 10 similar vocational colleges, the oldest of which opened in 1989.

Rihab University only offers Baccalaureate degrees, whereas Al Fanar offers a broader range of programmes, with the majority of students taking Certificates and Diplomas, rather than degrees. There are no tuition fees and everything students need is provided free-of-charge.

All the students at Rihab University and Al Fanar College are female UAE nationals, and most come straight from single-sex government schools, at the age of eighteen. The Chancellor of each institution is also the Minister of Higher Education, an Emirati educated in Britain. The academic staff below him are both male and female, in more-orless equal proportions, and almost all of them, including the Provost of Rihab University and the Director of Al Fanar College, are expatriates from English-speaking countries such as Britain, Ireland, USA, Canada, South Africa, Australia and New Zealand, employed on 
fixed-term, three-year contracts. Thus, appraisers and appraisees are both Westerns working temporarily within institutions located in an Arab-Islamic state.

\section{(iii) The Appraisal Systems}

At both sites, supervisors watch faculty teaching lessons and provide written feedback at least once a year, and usually once a semester. The feedback forms contain a list of statements and against each one, the supervisor writes a number from one to five, and then adds comments. In addition, student evaluations are sought every semester, using an online questionnaire with a Likert scale. There is also some element of teacher selfevaluation, focusing on teaching philosophy, quite generally, at Rihab, and on goalsetting, more specifically, at Al Fanar. In its first year, the appraisal system at Rihab included peer-appraisal, again using a questionnaire with a Likert scale, but this was discontinued thereafter. Peer appraisal was never used at Al Fanar, but the system there includes an annual report on one's performance, written by one's supervisor. This document has no direct parallel at Rihab.

In terms of outcomes, a memo sent to all teachers at Rihab stated that:

The purpose of the annual performance review is to assess each faculty member's overall contribution to the ongoing development of Rihab University, to help channel faculty efforts into those areas of most importance to the success of the institution, and to provide feedback to faculty in their efforts to improve. 
At Al Fanar, the purpose of appraisal was not so clearly documented, but at both institutions, interviewees said it was used primarily to inform decisions about probation and the renewal of three-year fixed-term contracts. At the time of the research, the appraisal systems did not affect salaries in any way, but performance-related pay was introduced at Rihab a year after the research finished.

\section{The Conceptual Framework}

\section{(i) The Purpose of Appraisal: Development versus Evaluation}

Despite the lack of consensus over definitions and purposes, a remarkably consistent dualism emerges from the literature between models of appraisal stressing professional development and models stressing evaluation / accountability. Hence, we find Peaker (1986, p.78) contrasting “improvement" and "accountability"; Pollitt (1987, p.94) contrasting "a professional development model" and "efficiency driven performance assessment"; Walsh (1988, p.352) contrasting "participative appraisal" and "managerial, control-oriented appraisal"; Hutchinson (1997, p.158-159) contrasting "professional development" and "managerialist" forms of appraisal; and Middlewood \& Cardno (2001, p.5) contrasting "professional development" and "accountability".

How far this dualism can or should be reconciled remains highly debatable. A minority of authors such as Powney (1991) suggest evaluative appraisal is inappropriate in education; many more, such as Pollitt (1987), Winter (1989a, 1989b), Lovich (1990), Fidler \& Cooper (1992), Randell et. al. (1994), Fletcher (1996), Sale (1997), Taylor (1997), Casey et. al. (1997) and Walker \& Dimmock (2000) suggest both approaches are acceptable, even necessary, but only as long as they are kept separate. Between these two extremes lie 
several authors, such as Peaker (1986), Turner \& Clift (1988), Wilson \& Beaton (1993), Goss (1994), Hughes (1998), Poster \& Poster (1997) and Mills \& Hyle (1999), who see no difficulty in conducting evaluative and developmental appraisal simultaneously. Each of these three perspectives will now be considered in more detail.

\section{(ii) Accountability as a Contested Value within the Global Rise of Managerialism}

The appraisal scheme adopted by any organisation will reflect the value system of that particular institution (Hughes, 1998; Hutchinson, 1997). It will also reflect "wider structural, economic and political frameworks" (Grace, 1985, p.3) because the practice of appraisal is affected not only by internal organisational values, but also by external cultures, traditions (including the public's respect for teachers, and the power of trade unions), and political imperatives (Middlewood \& Cardno, 2001, p.13-14).

Many authors view the introduction of appraisal as part of a wider reform process intended to increase levels of accountability and central control within education. This, in turn, is seen as one manifestation of a global trend towards greater managerialism throughout the public sector (Walsh, 1988; Pollitt, 1990; Wilson \& Beaton, 1993; Hutchinson, 1995; Randle \& Brady, 1997a, 1997b). According to Walsh (1988, p.367), "the development of appraisal systems is part of the development of a more managerial approach to education" and for Wilson \& Beaton (1993, p.164) "what is produced in appraisal is a new form of managerial discipline. The central component of the discipline is accountability".

When the purpose of appraisal is accountability, it is hardly surprising to find its underlying ideology being challenged by theorists and its practical implementation being 
resisted by practitioners. Managerialism has been attacked at a conceptual level for its general lack of coherence and its many internal contradictions, including its promise to deliver both greater delegation / local autonomy and more centralised control (Pollitt, 1993, p.111-113). It has also been criticised for failing to acknowledge fundamental differences between public services and private sector businesses (Clarke \& Newman, 1997), particularly in areas such as market-competition, the supply-income relationship, and "the distinctive status of citizenship in public-service transactions" (Pollitt, 1993, p.130).

Even at a practical level, there have been grave concerns about the increase in bureaucratic paperwork and the "fruitless and irksome" form-filling (Randle \& Brady, 1997b, p.133), described by lecturers as "busy work" detracting from the "main game" (Currie \& Vidovich's, 2000). Added to this is a strong sense that demands for accountability inhibit intellectual curiosity and creativity (Deem, 1998) and narrow the focus of research, away from what arouses curiosity and towards what has commercial application (Currie \& Vidovich, 2000).

Many of these criticisms of managerialism are reflected in initial reactions to the introduction of more formalized appraisal schemes. When appraisal retains its traditional focus on professional development, it enjoys considerable support, both in the literature and the staff-room. The studies undertaken by Rutherford (1988), Powney (1991), Magennis (1993) and Kyriacou (1995) all conclude that teachers are in favour of appraisal within the context of professional development. When appraisal acquires an externallyimposed focus on evaluation / accountability, however, the response is more mixed. Studies by Peaker (1986), Mortimore \& Mortimore (1991) and Middlewood (2001) all 
indicate that schoolteachers, in the USA and UK have accepted the need for both forms of appraisal, with $80 \%$ of Middlewood's sample saying evaluative appraisal was essential to ensure accountability. Likewise in American higher education, Mills \& Hyle (1999, p.362) assert that faculty members "seem to see the legitimacy and rationale for both types of reviews", whilst Australian faculty are reported as saying they are "not opposed to accountability per se" (Currie \& Vidovich, 2000, p.143). In UK further and higher education, by contrast, acceptance of evaluative appraisal has been somewhat slower. Indeed, Randle \& Brady (1997a, p.237), Elliott \& Crossley (1997, p.89) and Deem (2000, p.15) all note a sharp dichotomy between the values espoused by managers and lecturers writing, respectively, of "a conflict of paradigms", "a fundamental difference" and "some sharp contrasts".

(iii) The Separation of Developmental and Evaluative Appraisal at a Conceptual

\section{Level}

As noted above, not all writers see the value of evaluative appraisal, but, of those that do, most insist that the two approaches ought to be kept separate at all times. Pollitt (1987), Winter (1989a, 1989b), Lovich (1990), Fidler \& Cooper (1992), Randell et. al. (1994), Fletcher (1996), Sale (1997), Taylor (1997), Casey, et. al. (1997) and Walker \& Dimmock (2000) are typical of this stance.

Fidler \& Cooper (1992, p.3) write unequivocally about "the fundamental contradiction inherent in using appraisal for both evaluative and developmental functions". Likewise, Sale (1997, p.29) insists that combining development and assessment "is fatal to staff development and arguably inefficient and unfair as a means of assessment". This is 
because "The relationship between appraiser and appraisee for goals such as developing data for pay and promotion decisions appears to contradict the trusting relationship required for counselling appraisees in areas of organisational commitment and future development" (Taylor, 1997, p.56). In other words, "The imminence of reward decisions tends to block constructive discussion of developmental needs" (Fletcher, 1996, p.235).

(iv) The Combination of Developmental and Evaluative Appraisal at a Conceptual and / or Pragmatic Level

A sizeable minority of authors, including Peaker (1986), Turner \& Clift (1988), Wilson \& Beaton (1993), Goss (1994), Hughes (1998), Poster \& Poster (1997) and Mills \& Hyle (1999), are less convinced that this conceptual distinction can and should be maintained in practice. In some cases, the two functions are combined into a single (usually annual) appraisal cycle on pragmatic grounds, with defendants arguing that it would be just too costly, cumbersome and time-consuming to go through the process twice for different reasons. "It is, in part, the efficiency of including both forms of assessment in one review that makes evaluation acceptable and practical to conduct" (Mills \& Hyle, 1999, p.355).

In other instances, teachers and managers are said to believe that any form of developmental appraisal other than peer review will inevitably affect any form of evaluative appraisal, particularly if both are conducted by the same person. This being the case, it is better that such unavoidable influence be overt and acknowledged than covert and denied (Hughes, 1998, p.22). 
Moreover, according to Bryman et. al. (1991), Wilson \& Beaton (1993) and Goss (1994), many teachers think a positive appraisal should be linked to pay and promotion decisions, whilst many senior managers think a negative appraisal should be linked to sanctions (Wilson \& Beaton, 1993, p.178). Indeed, according to Hughes (1998, p.26), "Both appraisers and appraisees were aware of the limitations of some schemes, which were so concerned to be supportive, non-threatening and non-judgemental that poor performance was never confronted. This ineffectiveness brought the scheme into disrepute with everyone".

The literature cited above would seem to suggest that the rhetoric of appraisal rarely matches the reality, in that empirical studies often reveal evaluative and developmental elements being combined within the same process, despite strong exhortations from many writers to keep the two separate. In this regard, my own four-year study of HE appraisal in the United Arab Emirates represents an even greater challenge to the rhetoric of appraisal, since it reveals an established, seemingly successful scheme that most appraisees and appraisers say is wholly evaluative.

\section{The Study}

The four-year study used a combination of participant-observation, documentary analysis and interviewing at two different federally-funded HEIs. The first period of research, at Rihab University, involved interviews with five appraisers / managers and fourteen appraisees / teachers. Three of the appraisers were middle managers responsible for supervising a group of teachers; one was a more senior manager with overall responsibility for the department; and one was an academic advisor to the Provost with particular 
responsibility for faculty liaison. Sampling was not an issue with regard to the appraisers because I interviewed all of them; the appraisees were mostly a convenience sample of volunteers, though I approached the last two (male) appraisees directly in order to achieve a better gender balance.

The second period of research, at Al Fanar College, involved interviews with four appraisers / managers and fifteen appraisees. As at Rihab, three of the appraisers were middle managers responsible for supervising a group of teachers; and one was a more senior manager, with overall responsibility for the department. This time, however, the appraisees were selected using purposive sampling that took account of their gender, length of service, teaching programme and line manager.

The research followed a grounded theory approach, meaning that theory was inductively derived through an iterative process of data collection, analysis and theory-building (Glaser and Strauss, 1967; Strauss and Corbin, 1990). It therefore began with a research "phenomenon" (Strauss and Corbin, 1990, p.38), namely, faculty appraisal, rather than more specific research questions; concepts were allowed to "emerge from the data" (Strauss and Corbin, 1990, p.23) rather than being pre-determined; and analysis of the data from Rihab informed the subsequent collection of data from Al Fanar. At the end of this process, a number of themes had emerged, two of which will be discussed below. The first concerns how far, in principle, accountability models of appraisal are acceptable to either teachers or academic-managers; the second concerns how far, in practice, the specific appraisal scheme in each institution is perceived as developmental and / or evaluative.

The results of my research suggest that the similarities between the two institutions, in 
terms of how staff perceive appraisal, in general, and their respective schemes, in particular, far outweigh the differences, and for this reason, the findings from the two sites have usually been combined.

\section{The Findings}

\section{(i) The Acceptance of Accountability Models in Theory}

None of the 38 people interviewed voiced any opposition to the principle of appraisal. Amongst the teachers, appraisal was described quite often as "a necessary evil" and one person suggested it was like going to the dentist - not comfortable for the individual concerned, but "a good thing overall". It was said that some system of evaluation was necessary for any institution to function, and that management needed to know what teachers were doing, so they could ensure high quality teaching and learning. One faculty member asserted that "there has to be some way of knowing if a teacher is completely wacko", and another asked, with obvious emotion, "Why shouldn't an institution have an appraisal system to ensure quality among teachers? Why shouldn't it?"

Some faculty members drew explicit links between appraisal, evaluation and accountability, the following quotation being typical:

People get evaluated in their jobs all the time ... ... I'm not a business person at all. I fought it my whole life. But we're all accountable for our job, for what we do ... in every other job on earth, if you don't do your job well, you probably don't keep the same job. 
Indeed, one faculty member whose previous place of work had not conducted any form of appraisal thought she had become "unprofessional" as a result "because it didn't matter".

Similarly, the nine managers in the study were also strongly in favour of appraisal, one questioning how any institution could maintain any kind of quality without one, and another arguing that appraisal was necessary "if we are to regard ourselves as a profession".

Thus, teachers and managers agreed on the need for a process whereby management could collect evidence on teachers' performances in order to maintain standards. They disagreed, however, on the best way to judge the quality of teaching and learning; the extent to which teachers should be held accountable to different parties; and the amount of professional autonomy they should be afforded.

With regard to the quality of teaching and learning, four faculty members and one manager drew attention to a perceived difference between business and academia, one claiming that "you have two completely different mind-sets" and another claiming that although a salesman could persuade people to buy more cars, "you cannot control learning" in the same way. Indeed, in the words of a third participant, "We are not a factory producing - where you can do your nice little production management studies, and efficiency schedules and time surveys. You can't quite do that. Teaching doesn't work like that".

One of these teachers then went on to insist that pass rates were a poor indicator of teacher quality, agreeing with Turner \& Clift's (1988, p.98-99) contention that "Examination 
results are a measure of a long-term process and ... a very crude reflection of an individual teacher's input”. By contrast, a different faculty member said teacher appraisal should be based on test scores, as this was more "objective" and less "political" than other methods, such as the manager's summative report.

Most participants focused quite narrowly on the quality of the teacher. However, one faculty member did suggest such a narrow focus, though very prevalent, was actually unhelpful. In her eyes, appraisal:

should be about the quality of everything ... the quality of the materials you have ... the quality of the managerial support you have ... the quality of the appraisal even. But, it doesn't seem to be about any of that. It often comes down to the quality of the teaching and the quality of the teacher.

In this respect, she echoed the point made by Walsh (1988) and Simons \& Elliott (1989) regarding the need to judge a teacher's work in context, even though, this is very often not done, precisely because the appraiser is partly responsible for creating the working environment out of which inadequacies may have arisen (Burgess, 1989, p.29).

With regard to accountability, some faculty members seemed comfortable with making teachers accountable to the institution, whilst others said teachers should be first and foremost accountable to the particular students they taught. One of the managers made explicit reference to this dual interpretation of accountability, speaking of a "personal accountability to students" that "most teachers feel everyday of their lives", and contrasting this with an accountability to the values, goals and rules of the institution. She highlighted how these two kinds of accountability are often "at war", particularly in 
relation to institutional rules on things like attendance and exam resits, where some teachers, in her experience, let the allegiance they felt towards their own students over-ride institutional policies intended to serve the common good.

Opinion was also divided on the question of how much professional autonomy was desirable; how much professional autonomy teachers actually had; and whether any perceived curtailment of professional autonomy was part of a global rise in accountability, or merely the result of working in a particular Arab-Islamic context. Several faculty and three managers spoke of the need to trust teachers as competent professionals. However, two faculty members mentioned how the notion of professional autonomy could be misused by teachers. One said it was trumpeted by “people who don't like to be appraised [even though] you should open yourself up to other opinions". The other remarked on how "they call it professional autonomy, and what they really mean is 'I want to do exactly what I want to do. And you have no right to tell me what to do"'. Likewise, one senior manager suggested "too much professional autonomy leads to a whittling down of standards" particularly in relation to exam pass rates.

One faculty member and one manager mentioned the considerable freedom they thought teachers enjoyed in terms of curriculum delivery, though not curriculum content. By contrast, three faculty members said they had less freedom than they had had at previous institutions, but only one of them attributed this to the need for greater institutional accountability.

To sum up the findings in relation to the first research theme, neither faculty nor management appeared opposed to appraisal in principle. Nor were the perceptions of 
faculty and management in obvious conflict. Undoubtedly, opinions differed considerably on how to measure quality, and how to balance accountability and professional autonomy, but these differences were not split along partisan lines, in the way suggeseted by Randle \& Brady (1997a, 1997b), Elliott \& Crossley (1997) and Deem (2000).

\section{(ii) The Dominance of Evaluative Approaches in Practice}

Only two teachers said the current appraisal scheme was developmental. One of these teachers had received particularly detailed comments on an observed lesson, and the other had described an area of interest on her self-evaluation form and then been allowed to pursue this. Two other teachers said that although it was currently evaluative, in the past, with different managers, it had been much more developmental, as they had been given a more detailed critique of the observed lesson containing suggestions for improvement. They both thought the precise balance between evaluation and development was more a function of a particular manager's approach than a function of the system itself.

The remaining 25 teachers all said the appraisal system was far more evaluative than developmental, using phrases like "wholly evaluative" or "95\% evaluative". Within this group, five teachers at Rihab went on to point out that, in reality, it was neither evaluative nor developmental, because nothing was ever done with the information collected. In the words of one such teacher, "There's no purpose to this. It's just an exercise, because there is no feedback. It's just something they have to go through". 
Two teachers questioned whether such a well-qualified and experienced faculty had anything else to learn. Another questioned whether the working week allowed any time for professional development, echoing a common concern that even developmental appraisal can be onerous for teachers because the targets the institution encourages them to set themselves are not adequately resourced.

Notwithstanding the three comments above, twelve other teachers said they wished the appraisal system were more developmental, with more detailed feedback, especially after the classroom observation. One talked about "missed opportunities for development" and another said, "I feel like I have a lot to learn from people who have more experience than me. And if I have to go through the pain of observation, I'd a lot rather actually get something out of it".

None of these teachers saw any problem with combining evaluative and developmental elements within the same process. Indeed, of the 29 teachers interviewed, only one suggested that "appraisal" should be kept separate from "evaluation and assessment [and] whether you are going to pass your probationary year". In her view, such a separation was necessary to enable open and honest discussion:

I don't think you should be able to fail an appraisal. ... I think you should be able to say what you want, and your manager should be able to explore why you said certain things or why you feel certain things. But I think nothing that you say in your appraisal should count against you.

The situation was not quite so extreme amongst the managers. Two said their schemes were "in the middle" between development and evaluation, and five said they were 
predominantly evaluative. One middle manager placed the scheme "fairly high towards the evaluative and judgemental" end of the spectrum, especially when compared to the very developmentally-focused system she had used previously at a different institution. She went on to say, somewhat hesitantly, that she suspected senior management would not like publicly to admit how evaluative the system was because they were aware that this was not considered "best practice" in education. Interestingly, within the context of the confidential interview, the senior manager from the same insititution had no hesitation in declaring the apprasial system " $90 \%$ towards the evaluation and judgement end, overwhelmingly so". This, she felt, was justified because the institution was judged by their exam results and could not afford the luxury of letting 120 people engage in their own kind of professional development. Whether or not the manager would have publicly admitted to such an evaluative system remains unclear.

\section{(iii) The Politics of Appraisal in the UAE Context}

As previously reported, appraisal was viewed by almost all faculty and half the management as predominantly evaluative, predicated on a labour / craft model of teaching (House \& Lapan, 1989, p.56), being concerned with the maintenance of minimum standards of competency. Almost all faculty said that, when observed, they tried to give lessons showing themselves in the best possible light. "People do get the impression, rightly or wrongly, that it's a formulaic lesson they are looking for." Indeed, one new faculty member recounted how, after giving "a performance lesson" for her first observation, she had given "a regular lesson" for her second observation, and been told this was not quite right. The manager observing her had asked for a more detailed lesson plan, and other faculty had told her, "You're not supposed to do regular lessons. You're 
supposed to do performances ... when you are being observed you do a special observation lesson. It's not what you normally teach".

This emphasis on performance was also apparent in the comments from managers, one of whom said she told her faculty "it'll go in your evaluations, so yes, do an all-singing, alldancing [lesson]". Similarly, one senior manager likened a class visit to hosting a dinner party where 'I'm not going to bring out my broken crockery and cups - I'm going to get the best stuff". Clearly, neither teachers nor observers saw the class visit as an opportunity to engage in collaborative experimentation or critical reflection.

Moreover, two managers at Al Fanar commented on the fact that identifying any weakness in a teacher was enough to get them sacked. A senior manager talked of putting together a very successful action plan which helped turn around a probationary teacher, only to have the most senior member of the college dismiss her anyway. In her words, "identifying them as being at risk has more-or-less been their death-knell ... whatever they have done has not been enough to satisfy the management that it's good". The decision to fire the teacher had been taken long before the action plan had come to fruition. Likewise, one of the middle managers recognised that:

Instead of allowing time for problems with one particular teacher to work themselves out, PD, support, help and so on, depending again on who's up at the top ... the minute anything, any problem is mentioned at appraisal, it's bye bye. 
In similar vein, one of the appraisers at Rihab admitted giving top marks to everyone, during the class visit, because anything else "could so easily be misinterpreted" at a later

stage. Judging by the fact that all but one of the teachers at Rihab who discussed their numerical rating said they got top marks in all categories of the lesson observation form, this appraiser was certainly not the only one to adopt such a strategy.

Thus, it would seem that appraisal need not automatically operate on the basis of the deficit model of teaching, but did so at Rihab and Al Fanar because of the particular organisational context. In other words, the more evaluative the appraisal system, and the more punitive the overall organisational culture, the greater the concentration on basic competency, the greater the lack of constructive feedback, and, paradoxically, the greater the temptation for those appraisers committed to professional development to avoid documenting poor performance.

\section{(iii) Appraisal and the Paradox of Continuing Professional Development.}

Much of the rhetoric about appraisal emphasizes its developmental function, and its potential to improve teaching and learning. As previously stated, only two teachers considered their current system of appraisal in any way developmental. By contrast, several teachers and three managers expressed the opinion that people deemed not to be working at the right level would simply be asked to leave, without any opporunity to improve their performance. The comments of the manager at Al Fanar are particularly apposite in this respect, and worth quoting in full:

To a certain extent, we are saying to people, this is the level of performance 
we expect, right from the beginning and through our appraisal system, we are looking to see if you meet that standard, and if you don't, there's not an awful lot we can do about it, really ... I think it's political basically, They pay good salaries and they can afford to say, okay, we'll give you this, but this is what we expect in return. And we're not really interested in having to develop people because we can get other people who are as good or better. I think it's simple economics ... I have mixed feelings about that. Because in previous organisations I've worked for, it's not been like that, and we have worked with people. And I think, you know, it's obviously much more preferable to work with people and develop them. The problem is, that while you're doing that, students can be suffering. And I think that's fair enough, you know, if it might take somebody a year to come up to an acceptable standard of teaching, and in the meantime, the students could be getting more from another teacher who's already there.

Likewise, another of the managers at Al Fanar suggested that the institution needed better than average teachers because the students had had such poor teaching in government schools. In her words:

There will always be good teachers and bad teachers, and there will always be average teachers. And the stakes here are higher because our learners have so many difficulties and because they are not independent learners. And because they are so immature, because their experiences have been so paltry in education, so the stakes are higher. We need better teachers, it's as simple as that. Students in other areas, or other countries that could get away with an average or even a mediocre teacher, it just doesn't happen 
here. They have to have the best, if we're going to succeed.

The implication that certain institutions have the right to employ only the very best teachers has huge ramifications for the profession, and challenges the very concept of CPD. On the one hand, it has become something of a mantra in education that all teachers should continually enhance their skills. On the other, it goes almost without saying that any educational institution that makes teaching its highest priority will seek to employ only the best possible classroom practitioners.

How these two apparently contradictory ideals might be reconciled is far from obvious. Hughes (1998, p.25) writes of the "need to proclaim that 'you don't have to be bad to get better!'", but this sidesteps three crucial questions. The first is whether student learning is compromised during the time it takes adequate teachers to become excellent; the second is whether educational establishments have a responsibility to the teaching profesion as a whole, and not just the individual learners enrolled in their classes; the third is whether certain institutions should be allowed to 'cherry pick' only the best teachers, because of their greater financial bargaining power, or alledgedly more disadvantaged students. None of these questions has an obvious answer, but the striking suggestion that students may experience less than optimal learning opporunities while teachers are being developed ought not to be ignored.

\section{Discussion}

This paper has examined how faculty appraisal is perceived by teachers and academic managers at two higher education institutions in the United Arab Emirates. It has 
concluded that neither teachers nor academic managers are in any way opposed to the principles of accountability and evaluative appraisal. Nor do they see any difficulty in combining developmental and evaluative approaches, despite the dire warnings found in much of the literature.

It would seem that the primary purpose of appraisal in UAE higher education is to ensure certain standards of performance are maintained. This purpose is fulfilled with ease because institutions have the money to attract more teachers than they need, and the legal right to dismiss anyone for any reason. All of this is understood and accepted by Western teachers and academic managers, despite the fact that, in their home countries, appraisal is intended to be much more developmental, and employees are much more protected by government legistlation, industrial tribunials and trade unions.

The original research did not probe why the participants were generally so accepting of such evaluative appraisal, but several reasons spring to mind. Appraisers may have endorsed it because of a conviction that these particular students deserve only the very best teachers on account of the generally poor standard of education in government schools. Appraisees may have accepted it because of other compensations, such as the high tax-free salaries, small class sizes, excellent teaching resources, and state-of-the-art IT facilities. Moreover, expatriate teachers in the UAE are only ever offerered fixed-term contracts of three-years duration. In such circumstances, it is hardly surprising that the provision and take-up of CPD is much more limited than the human resource management (HRM) literature advocates. 
Interestingly, this lack of professional development does not appear to have affected the success of either institution. During the time of the research, both Rihab and Al Fanar were over-subscribed in terms of students wanting to study there and teachers wanting to work there. The research at Rihab took place during its second and third year of operation, so graduation rates were not available, but student progression rates did not seem a major cause for concern. At Al Fanar, graduation rates were healthy, and value-added measures were amongst the highest in the country for similar federally funded institutions.

Much of the rhetoric about appraisal, in particular, and HRM, in general, stresses how "very precious" (Woodward, 1991, p.120) people are to the success of an organisation; and how much they should be nurtured. Bush and Middlewood (1997, p.ix) are typical of this stance when they write that, "Sensitive management of people as individuals with different personalities, backgrounds and personal and professional needs is a vital dimension of the development of successful organisations". What the research cited above shows is that this sentiment is by no means a universal truth. It is possible for an educational organisation to be successful, even when its teachers have virtually no job security, and endure a highly evaluative appraisal system, with very few opportunities for professional development, just so long as it compensates by offering a high salary, excellent teaching facilities, and the chance to live in a very different culture.

\section{Acknowledgements:}

I would like to thank Clive Dimmock and David Hellawell for their feedback on earlier drafts of this article. I would also like to thank the editor, Douglas Davis, for his very helpful advice and summary of the reviewers' comments. 


\section{References}

Bryman, A., Haslam, C. \& Webb, A. (1991) University Staff Appraisal Final Report, Department of Social Sciences, University of Loughborough.

Burgess, R. (1989) 'A problem in search of a method or a method in search of a problem? A critique of teacher appraisal' in Simons, H. \& Elliott, J. (eds.) Rethinking Appraisal and Assessment, Milton Keynes, Open University Press.

Bush, M. and Middlewood, D. (eds.) (1997) Managing People in Education, London, Paul Chapman Publishing.

Casey, R.J., Gentile, P. \& Bigger, S.W. (1997) Teaching appraisal in higher education: an Australian perspective, Higher Education, 34 (4), 459-482.

Clarke, J. \& Newman, J. (1997) The Managerial State, London, Sage Publications Incorporated.

Currie, J. \& Vidovich, L. (2000) Privatization and competition policies for Australian universities, International Journal of Educational Development 20 (2000), 135-151.

Deem, R. (1998) 'New managerialism' and higher education: the management of performance and cultures in universities in the United Kingdom, International Studies in Sociology of Education, 8 (2), 47-70. 
Deem, R. (2000) 'New Managerialism' and the Management of UK Universities, End of Award Report of the Findings of an ESRC Funded Project, Department of Education Research and the Management School, Lancaster University.

Elliott, G. \& Crossley, M. (1997) Contested values in further education, Educational Management and Administration, 25 (1), .79-92.

Fidler, B. (1989) 'Staff appraisal - theory, concepts and experience in other organisations and problems of adaptation to education', in Riches, C. \& Morgan, C. (eds.) Human Resource Management in Education, Milton Keynes, Open University Press.

Fidler, B. \& Cooper, R. (eds.) (1992) Staff Appraisal and Staff Management in Schools and Colleges: a guide to implementation, Harlow, Longman.

Findlow, S. (2005) International networking in the United Arab Emirates higher education system: global-local tensions, Compare, 35 (3), 285-302.

Fletcher, C. (1996) 'Appraisal: an idea whose time has gone?', in Billsberry, J. (ed.) The Effective Manager, London, Sage Publications Limited.

Glaser, B. G. and Strauss, A. (1967) The Discovery of Grounded Theory, Chicago, Aldine.

Goss, D. (1994) Principles of Human Resources Management, New York, Routledge. 
Grace G. (1985) Judging teachers: the social and political contexts of teacher evaluation, British Journal of Sociology of Education, 6 (1), 3-16.

Gutierrez, K., Baquedano-Lopez, P. \& Tejeda, C. (1999) Rethinking diversity: hybridity and hybrid language practices in the third space, Mind, Culture and Activity, 6(4), 286303.

Hofstede, G. (1991) Cultures and Organisations: software of the mind, Maidenhead, McGraw-Hill Book Company (UK) Limited.

Hofstede, G. (1996) "The cultural relativity of organizational practices and theories" in Billsberry, J. (ed.) The Effective Manager: Perspective and Illustrations, London, Sage Publications Ltd.

Hofstede, G. (2005) Cultures and Organisations: software of the mind, Second Edition, Maidenhead, McGraw-Hill Book Company (UK) Limited.

House, E. \& Lapan, S. (1989) 'Teacher Appraisal' in Simons, H. \& Elliott, J. (eds.) Rethinking Appraisal and Assessment, Milton Keynes, Open University Press.

Huberty, C.J. (2000) An approach to annual appraisal and evaluation of university faculty, Journal of Personnel Evaluation in Education, 14 (3), 241-251.

Hughes, P. (1998) Appraisal in UK Higher Education, Sheffield, Universities' and Colleges' Staff Development Agency. 
Hutchinson, B. (1995) Staff appraisal: personal, professional and organisational development?, Educational Management and Administration, 23 (1), 47-57.

Hutchinson, B. (1997) 'Appraising appraisal: some tensions and some possibilities', in Kydd, L., Crawford, M. \& Riches, C. (eds.) Professional Development for Educational Management, Buckingham, Open University Press.

Kyriacou, C. (1995) An evaluation of teacher appraisal in schools within one Local Education Authority, School Organisation, 15 (2), 109-116.

Lovich, N.P. (1990) 'Performance Appraisal' in Hays, S.W. \& Kearney, R.C. (eds.) Public Personnel Administration: problems and prospects, New Jersey, Prentice Hall.

Magennis, S. (1993) 'Appraisal systems and their contribution to quality in teaching', in Ellis, R. (ed.) Quality Assurance in University Teaching, Buckingham, The Open University Press.

Middlewood, D. (2001) 'Appraisal and Performance in the UK' in Middlewood, D. \& Cardno, C. Managing Teacher Appraisal and Performance, London, RoutledgeFalmer.

Middlewood, D. \& Cardno, C. (2001) Managing Teacher Appraisal and Performance, London, RoutledgeFalmer. 
Miles.M. \& Hyle, A.E. (1999) Faculty appraisal: a prickly pair, Higher Education, $38,351-371$.

Mortimore, P. \& Mortimore, J. (1991) Teacher appraisal: back to the future, School Organisation, 11 (2) 125-143.

Peaker, G. (1986) Teacher management and appraisal in two school systems in the southern USA, Journal of Education for Teaching, 12 (1), 77-83.

Pollitt, C. (1987) The politics of performance assessment: lessons for higher education, Studies in Higher Education, 12 (1), 87-98.

Pollitt, C. (1990) Managerialism and the Public Services: The Anglo-American experience, Oxford, Blackwell.

Pollitt, C. (1993) Managerialism and the Public Services (Second Edition), Oxford, Blackwell.

Poster, C. \& Poster, D. (1997) 'The nature of appraisal', in Kydd, L., Crawford, M. \& Riches, C. (eds.) Professional Development for Educational Management, Buckingham, Open University Press.

Powney, J. (1991) The appraisal of teachers in middle management roles, Research Papers in Education, 6 (3), 171-195. 
Randell, G., Packard, P. \& Slater, J. (1984) Staff Appraisal, London, IPM.

Randle, K. \& Brady, N. (1997a) Further Education and the new managerialism, The Journal of Further and Higher Education, 21 (2), 229-239.

Randle, K. \& Brady, N. (1997b) Managerialism and professionalism in the 'Cinderella Service', Journal of Vocational Education and Training, 29 (1), 121-139.

Rutherford, D. (1988) Performance appraisal: a survey of academic staff opinion, Studies in Higher Education, 13 (1), 89-100.

Rutherford, D. (1992) Appraisal in action: a case study of innovation and leadership, Studies in Higher Education, 17 (2), 201-210.

Sale, J. (1997) Appraisal Matters, Managing Schools Today, 6 (7), 28-29.

Simons, H. \& Elliott, J. (eds.) (1989) Rethinking Appraisal and Assessment, Milton Keynes, Open University Press.

Strauss, A. and Corbin, J. (1990) Basics of Qualitative Research: grounded theory procedure and techniques, California, Sage Publications Limited.

Taylor, H. (1997) A case study in the development of a staff appraisal system, Journal of Further and Higher Education, 21 (1), 55-61. 
Taylor, J. (2001) The Impact of performance indicators on the work of university academics: evidence from Australian universities, Higher Education Quarterly, 55 (1), 42-61.

Turner, G. \& Clift, P. (1988) Studies in Teacher Appraisal, Lewes, The Falmer Press

Walker, A. \& Dimmock, C. (2000) One size fits all? Teacher appraisal in a Chinese culture, Journal of Personnel Evaluation in Education, 14 (2), 155-178.

Walsh, K. (1988) 'Appraising the teachers: professionalism and control', in Dale R, et al. (eds.) Frameworks for Teaching, Milton Keynes, The Open University Press.

Wilson, F. \& Beaton, D. (1993) The theory and practice of appraisal: progress review in a Scottish university, Higher Education Quarterly, 46 (2), 163-189.

Winter, R. (1989a) 'Teacher appraisal and the development of professional knowledge', in Carr, W. (ed.) Quality in Teaching, London, Falmer Press.

Winter, R. (1989b) 'Problems in teacher appraisal: an action-research solution?', in Simons, H. \& Elliott, J. (eds.) Rethinking Appraisal and Assessment, Milton Keynes, Open University Press.

Woodward, M. (1991) Staff development in Further Education, in Bell, L. and Day, C. (eds.) Managing the Professional Development of Teachers, Milton Keynes, Open University Press. 